\title{
Neuropathic pain evaluation tools
}

\author{
Instrumentos de avaliação da dor neuropática \\ Fabiola Dach Eckeli', Rosimary Amorim Teixeira² ${ }^{1}$, Áquila Lopes Gouvêa ${ }^{3}$
}

\section{ABSTRACT}

BACKGROUND AND OBJECTIVES: Pain is a subjective symptom which may be measured by means of its several features, such as intensity, quality, location, duration and impact on daily activities. Due to the lack of means to better classify such symptoms, several studies have used intensity as the only evaluation measurement. To develop other types of research it was necessary the development of new tools to identify and measure remaining domains of pain. This review aimed at describing and analyzing available tools for neuropathic pain diagnosis and evaluation.

CONTENTS: Several tools were developed to evaluate neuropathic pain. Among them there are those validated for neuropathic pain in general, such as Leeds Assessment of Neuropathic Symptoms and Signs Pain Scale and its self-report version (self-administered LANNS), Douleur Neuropathique 4 Questions, Neuropathic Pain Questionnaire and its short form (NPQshort form), painDetect and ID-Pain. These are the most widely used tools worldwide for having a cutoff point, which makes them more objective tools. Other tools are Neuropathic Pain Scale, Pain Quality Assessment Scale and Neuropathic Pain Symptom Inventory. Tools translated and validated for the Portuguese language are Leeds Assessment of Neuropathic Symptoms and Signs Pain Scale, Douleur Neuropathique 4 Questions and Neuropathic Pain Symptom Inventory.

CONCLUSION: There are several tools which may be used to screen neuropathic pain, while others were developed for its evaluation. Among them there are those more objective and more commonly used. Some of these tools were translated and validated for the Brazilian Portuguese language. Keywords: Pain, Pain measurement, Scale.

\section{RESUMO}

JUSTIFICATIVA E OBJETIVOS: Dor é um sintoma subjetivo que pode ser mensurado por meio de suas várias características, como intensidade, qualidade, localização, duraçáo e impacto nas atividades diárias. Devido à falta de meios para caracterizar com maior propriedade esses sintomas, vários estudos se utilizaram da intensidade como sua única medida de avaliação. Para o desenvolvimento de outros tipos de pesquisa, fazia-se necessária a elaboração de novos instrumentos para identificação e mensuração dos demais domínios da dor. O objetivo desta revisão foi a descrição e análise dos instrumentos disponíveis para o diagnóstico e avaliaçấo de dor neuropática.

CONTEÚDO: Inúmeros instrumentos foram desenvolvidos para a avaliação da dor neuropática. Dentre eles estão aqueles que foram validados para dores neuropáticas em geral, como a Leeds Assessment of Neuropathic Symptoms and Signs Pain Scale e sua versão autoaplicável (self-administered LANNS), o Douleur Neuropathique 4 Questions, o Neuropathic Pain Ques-

1. Universidade de Sáo Paulo, Faculdade de Medicina de Ribeirăo Preto, Departamento de Neurociências e Ciências do Comportamento, Ribeirão Preto, SP, Brasil.

2. Hospital A C Camargo, Membro do Departamento da Central da Dor, Hospital do Servidor Público Estadual, Enfermeira do Grupo de Dor da Neurocirurgia, Sáo Paulo, SP, Brasil.

3. Universidade de Sáo Paulo, Faculdade de Medicina, Hospital das Clínicas, Enfermeira da Equipe de Controle de Dor - Divisăo de Anestesia. Sáo Paulo, SP, Brasil.

Conflict of interests: none-Sponsoring sources: none.

Correspondence to:

Fabíola Dach Eckeli

Departamento de Neurociências e Ciências do Comportamento, Hospital das Clínicas ( $4^{\circ} \mathrm{A}$ ), campus da Universidade de São Paulo. Avenida Bandeirantes, 3900

14048-900 Ribeirăo Preto, Sáo Paulo, Brasil.

E-mail: fabioladach@usp.br

(C) Sociedade Brasileira para o Estudo da Dor tionnaire e sua versão mais curta (NPQ-short form), o painDetect e o IDPain. Esses são os mais utilizados internacionalmente por apresentarem um ponto de corte, o que os torna instrumentos mais objetivos. Os demais instrumentos são a Neuropathic Pain Scale, a Pain Quality Assessment Scale e o Neuropathic Pain Symptom Inventory. Os instrumentos traduzidos e validados para o português são a Leeds Assessment of Neuropathic Symptoms and Signs Pain Scale, o Douleur Neuropathique 4 Questions e o Neuropathic Pain Symptom Inventory.

CONCLUSÃO: Há diversos instrumentos que podem ser utilizados para o rastreio de dor neuropática; outros foram desenvolvidos para sua avaliação. Dentre eles há aqueles mais objetivos e mais utilizados. Alguns desses instrumentos foram traduzidos e validados para o português do Brasil.

Descritores: Dor, Escala, Mensuraçóes da dor.

\section{INTRODUCTION}

Pain is a subjective symptom which may be measured by means of its different domains, such as intensity, quality, site and duration. These features, associated to other clinical history information, to general and neurologic physical evaluation and to detailed sensitivity exam are used to differentiate types of pain ${ }^{1}$. Since neuropathic pain (NP) diagnosis is time consuming and depends on additional tests ${ }^{1,2}$, the development of tools to screen NP could help identifying individuals with higher probability of having this pain $^{3}$.

During the 1970 s, as from the development of McGill Pain questionnaire ${ }^{4}$, it has become apparent that some pain descriptors were more frequent in cases of NP, such as tugging, pricking and burning ${ }^{5,6}$.

Although there are easy to identify NP, such as postherpetic neuralgia, others are less evident and bring diagnostic difficulties, especially for professionals without the necessary knowledge for neurologic exam ${ }^{1}$. So, the development of specific tools to evaluate NP could allow the identification of this type of pain in a simple and fast way ${ }^{7}$, resulting in benefits for the clinical practice and in the development of new clinical trials.

To date, seven tools were developed to differentiate NP from non-neuropathic pain, and three more to describe $\mathrm{NP}^{8}$. Among ten NP evaluation tools, four were translated and validated to Brazilian Portuguese $e^{9-12}$.

This article aimed at describing tools developed for the initial evaluation of NP patients. Some of them were validated for specific neuropathic pains, but this article shall focus on those validated for NP in general.

\section{LANSS AND S-LANSS}

The Leeds Assessment of Neuropathic Symptoms and Signs (LANSS) Pain Scale is a tool aiming at differentiating NP from non-neuropathic pain. This tool takes 30 minutes to be applied and is based on the analysis of sensitivity description and on sensory deficits evaluation ${ }^{13}$. Five groups of symptoms are considered, namely dysesthesia, allodynia, paroxysmal pain, autonomic changes and burning sensation at painful site. With regard to physical evaluation, two items are taken into consideration: allodynia and changes in pain threshold at needle pricking ${ }^{13}$. The contralateral area to that where pain is referred is used as control. Answers to this questionnaire are binary and refer to pain felt in the last week. Score varies from zero to 24 , being that scores below 12 suggest that it is improbable that pain has neuropathic origin ${ }^{13}$. On the other hand, scores equal to or above 12 mean that neuropathic mechanisms would be involved in patient's pain. LANSS was able to identify $80 \%$ of NP cases, resulting in $85 \%$ sensitivity and $80 \%$ specificity as compared to clinical diagnosis ${ }^{13}$. LANSS was criticized for being time consuming, for being difficult to apply in symmetric neuropathies and for using sharp needle, which would go against best medical practices. These criticisms were refuted by the author ${ }^{14}$.

In addition to Portuguese, LANSS scale was translated into Spanish ${ }^{15}$ and 
Turkish $^{16}$. Portuguese version of Brazilian LANSS is considered reliable to be used in clinical practice and research ${ }^{11}$.

Due to the need for training to apply LANSS, there could be difficulties to use such tool in some clinical situations and in research ${ }^{17}$. Aiming at overcoming this problem, a self-administered version was developed (selfadministered LANSS or S-LANNS) containing the same five items related to quality of pain. Items related to pain area evaluation were modified to allow the self-examining of patients during allodynia investigation ${ }^{17}$. The weakness of this tool would be that patients should only characterize their worst pain, which could impair the identification of some cases of not so severe $\mathrm{NP}^{18}$. In its initial descriptions, S-LANNS has shown $57 \%$ sensitivity and $69 \%$ specificity in administration via mail; when administered via telephone has show $52 \%$ sensitivity and $78 \%$ specificity as compared to clinical diagnosis ${ }^{17}$.

\section{DN4}

The Douleur neuropathique 4 questions (DN4) is a tool aiming at screening NP. It may be used both by specialists and non-specialists ${ }^{1,19}$. It is made up of seven items related to symptoms and three items related to physical evaluation. Each item is scored 1 if the answer is positive and zero if negative, leading to a minimum score of zero and maximum of 10 . Cutoff point is four, being that scores equal to or above 4 suggest NP ${ }^{19}$. Due to the discriminative property of the first seven items, these could be used in some types of clinical trials, however this still needs to be validated. DN4 has $83 \%$ sensitivity and $90 \%$ specificity as compared to medical diagnosis ${ }^{19}$. DN4 was translated and validated to Portuguese aiming at introducing a reliable tool in the clinical scenario, giving priority to accurate diagnosis, helping the distinction between neuropathic and nociceptive pain ${ }^{10}$. Results of the Portuguese version validation have shown $100 \%$ sensitivity and 93.2\% specificity, being also able to identify NP patients ${ }^{10}$.

According to a systematic review, evidence level for construct validity, internal consistency and reliability was low or very low among different transcultural adaptations or translations ${ }^{20}$. However, the Portuguese version ${ }^{10}$ was the most satisfactory among non-French versions ${ }^{20}$.

\section{NPQ AND NPQ-S}

The study for the development of the Neuropathic Pain Questionnaire (NPQ) aimed at investigating factors to be used as basic descriptions by painful patients themselves ${ }^{21}$. It also tried to establish best and most commonly used descriptors to distinguish neuropathic from non-neuropathic pain $^{21}$ In addition to helping separate neuropathic from non-neuropathic pain, the tool aims at supplying a general evaluation of pain symptoms ${ }^{21}$. The questionnaire is made up of 32 questions of which 12 are selected. From these, 10 questions on quality of pain and 2 about changes in sensitivity ${ }^{21}$. It was originally developed in English in the United States, with $74.7 \%$ sensitivity and $77.6 \%$ specificity $^{21}$. It has also versions in Chinese, Italian and Swedish, however with less evidence that the original version. Properties of this tool were evaluated in individuals with a variety of chronic pain conditions ${ }^{20}$.

The Neuropathic Pain Questionnaire - Short form (NPQ-S) was originally developed in the United States as from a discriminative analysis of the 12 NPQ questions ${ }^{21,22}$. Among these, three were considered significant to differentiate neuropathic from non-neuropathic pain, namely: 1. Is your pain tingling? 2. Do you feel numbness at pain site? 3. Is pain worsened with touch? Discriminative function of this tool was able to estimate $64.5 \%$ sensitivity and $78.6 \%$ specificity and total forecast accuracy of $73.0 \%{ }^{22}$.

\section{PD-Q}

The Pain Detect Questionnaire (PD-Q) is a questionnaire developed in Germany initially to evaluate low back pain patients ${ }^{23}$. It is simple, useful and self-administered, allowing the detection of NP components in chronic pain patients ${ }^{23,24}$. It has sensitivity, specificity and positive predictive value of approximately $80 \%{ }^{23,25}$. It is made up of questions related to pain intensity, course and irradiation, in addition to presence and perceived severity in seven NP symptoms classified in a six-score Likert scale ${ }^{23}$. For diagnostic purposes, total score is calculated varying between zero and 38 based on patients' answers. When total score is above 18 , this means that a NP com- ponent is probable, while scores below 13 indicate that NP is improbable ${ }^{23}$. $\mathrm{PD}-\mathrm{Q}$ is divided in four major sections. The first has three items in the 11 -score Likert scale with extremities of the scale (zero=no pain, $10=\max$ imum pain), followed by color graduation in a scale representing pain intensity in analog format ${ }^{23}$. These items evaluate pain intensity at the moment, pain intensity mean and maximum during the last four weeks ${ }^{23}$. The second section asks patients to mark one of four charts which best describe their pain pattern. Scores are determined as follows: persistent pain with minor fluctuations (zero), persistent pain with peaks of pain $(-1)$, pain attacks without pain between them (1) and pain attacks with pain between them $(1)^{23}$.

The third section includes a sensory map represented by a homunculus, together with questions asking to mark pain zone, relating it to the presence of irradiation, in addition to showing the direction of irradiated pain with an arrow $^{23}$. Positive answer is scored with two points. In the last section there are seven items asking about the intensity of the sensation marked on the homunculus ${ }^{23}$. These items are scored with a 6-point Likert scale, with values corresponding to the following terms $(0=$ no, $1=$ had not noticed, 2 = a little, $3=$ moderately, $4=$ strong, $5=$ very strong ${ }^{23}$. These items ask about the following sensations: smarting, tingling, allodynia, pain attacks, temperature-evoked pain, numbness and pressure-evoked pain. This latter section has scores between zero and $35^{23}$.

\section{ID PAIN}

ID Pain is a questionnaire to evaluate patients with pain to differentiate nociceptive from neuropathic pain ${ }^{26}$. This questionnaire is still not validated in Brazil, but international studies have considered it comparable to other NP evaluation scales ${ }^{27}$.

It relates patients' pain characteristics with scores varying from -1 to $5^{26}$. This scale has sensitivity and specificity of approximately 70 to $80 \%$, and may be a useful tool to diagnose NP. Items include: 1 - "Is pain jumping or pricking"? 2 - "Does it have warmth or burning sensation"? 3 - "Do you feel numbness"? 4 - Is there electric shock sensation"? 5 - "Is pain worsened with the touch of clothes or bedding"? and 6 - "Is pain limited to joints"? ${ }^{1,3}$. One point is given to each affirmative answer for items 1 to 5 and -1 (minus one) for item $6^{26}$. For scores between 4 and 5 , NP is considered highly probable; between 2 and 3 it is considered probable; scores equal to 1 are considered possible and between zero and -1 are considered improbable ${ }^{26}$.

Table 1 shows sensitivity and specificity of each NP evaluation tool as compared to medical diagnosis.

Table 1. Sensitivity and specificity of tools for neuropathic pain detection

\begin{tabular}{|c|c|c|}
\hline Tools & $\begin{array}{c}\text { Sensitivity } \\
(\%)\end{array}$ & $\begin{array}{c}\text { Specificity } \\
(\%)\end{array}$ \\
\hline LANSS $^{13}$ & 85 & 80 \\
\hline S-LANSS via mail ${ }^{17}$ & 57 & 69 \\
\hline S-LANSS via telephone ${ }^{17}$ & 52 & 78 \\
\hline DN $4^{19}$ & 83 & 90 \\
\hline $\mathrm{PQ}^{21}$ & 74.7 & 77.6 \\
\hline NPQ- short ${ }^{22}$ & 64.5 & 78.6 \\
\hline PainDETECT ${ }^{23}$ & 85 & 80 \\
\hline ID Pain'26 & 81 & 65 \\
\hline
\end{tabular}

\section{NPS}

The Neuropathic Pain Scale (NPS) was developed to evaluate different pain qualities associated to NP. This was the first tool specifically designed for this objective.

NPS has a total of 10 items, being that two evaluate pain dimensions (intensity and discomfort) and eight evaluate NP quality (stabbing, burning, freezing, boring, tender, itching, deep pain, superficial pain). Items are evaluated by a numeric scale from zero to 10 . For example, for "hot", zero would be not hot and 10 very hot, or "worst imaginable sensation" to describe "too hot" pain ${ }^{28}$. 
PQAS

The Pain Quality Assessment Scale (PQAS) ${ }^{29}$ is a self-report tool derived from $\mathrm{NPS}^{28}$. PQAS was developed to evaluate the quality of NP not evaluated by the NPS scale ${ }^{29}$. Pain Quality Assessment Scale (PQAS) was translated and culturally adapted to Brazil but is still being validated ${ }^{12}$.

PQAS is able to evaluate qualities or domains affected by pain management ${ }^{29}$. It has 20 descriptors to evaluate two global aspects (intensity and discomfort), two spatial aspects (superficial and deep), and 16 quality domains: 1. Jumping (pricking, drilling); 2. Burning (on fire); 3. Dull; 4. Cold (freezing); 5. Tender (as open sore); 6. As a wound; 7. Itching (as "mosquito bite"); 8. Tugging; 9. Numbness; 10. Shock (lightning, spark); 11. Tingling; 12. Cramping (crushing, pressing); 13. Radiating; 14. Throbbing; 15. Hurting (as toothache); 16. Heavy (pressure) ${ }^{12}$.

PQAS has also an item to evaluate pain temporal pattern ("intermittent with no pain in other moments", "minimum pain the whole time with exacerbation periods" and "constant pain which does not change a lot from a moment to the other" ${ }^{29}$. Each item is evaluated by the verbal numeric scale where $0=$ "no pain" or "no painful sensation" and 10 = "worst imaginable pain sensation"12,29.

\section{NPSI}

The Neuropathic Pain Symptom Inventory (NPSI) was developed and validated to evaluate the effects of NP syndromes management ${ }^{30}$. This is the only tool validated for central and peripheral $\mathrm{NP}^{30}$.

NPSI was developed by French and Belgian specialists. The initial version had 18 descriptors and $4 \mathrm{NP}$ dimensions: spontaneous pain (burning, painful cool, pressure, pressing, cramps and dulling), spontaneous paroxysmal (electric shock, shooting, stabbing, piercing pain), provoked pain or worsened by touching the painful area (brushing, pressure, contact with something cold, contact with something warm), evaluate paresthesia and dysesthesia in painful area (pins and needles, tingling, numbness, itching) ${ }^{30}$. Final NPSI version included 12 items in total: 10 are differential symptoms descriptors and 2 items evaluate spontaneous and paroxysmal spontaneous pain ${ }^{30}$.

The tool evaluates mean pain intensity in the last $24 \mathrm{~h}$ in a verbal numeric scale from zero (no pain) to 10 (worst imaginable pain). Total pain intensity score may be calculated by the sum of 10 descriptors $^{30}$.

The validation process of the Portuguese version has shown that the self-applicable version is valid, reliable and sensitive to changes in both central and peripheral NP'.

\section{CONCLUSION}

Described tools may be used to screen NP cases, especially when used by nonspecialists. Seven of them were validated for NP in general and three for specific types of NP. These tools differ among themselves with regard to application time and mode, as well as to the ability to detect NP. Since up to $20 \%$ of NP cases are not identified by such tools, these cannot be used to replace clinical diagnosis. These tools should be used in the version validated to the language of the country where they will be applied, being that in Brazil we have available versions of LANSS, DN4, NPSI and PQAS.

\section{REFERENCES}

1. Haanpää M, Attal N, Backonja M, Baron R, Bennett M, Bouhassira D, Cruccu G, et al. NeuPSIC guidelines on neuropathic pain assessment. Pain. 2011;152(1):14-27.

2. Backonja MM, Attal N, Baron R, Bouhassira D, Drangholt M, Dyck PJ, et al. Value of quantitative sensory testing in neurological and pain disorders: NeuPSIG consensus. Pain. 2013;154(9):1807-19. Bennett MI, Attal N, Backonja MM, Baron R, Bouhassira D, Freynhagen R, et al. Using screening tools to identify neuropathic pain. Pain. 2007;127(3):199-203.

4. Melzack R. The McGill Pain Questionnaire: major properties and scoring methods. Pain. 1975;1(3):277-99.

5. Boureau F, Doubrère JF, Luu M. Study of verbal description in neuropathic pain. Pain 1990;42(2):145-52.

6. Dubuisson D, Melzack R. Classification of clinical pain descriptions by multiple group discriminant analysis. Exp Neurol. 1976;51(2):480-7.

7. Galer BS, Gianas A, Jensen MP. Painful diabetic polyneuropathy: epidemiology, pain description, and quality of life. Diabetes Res Clin Pract. 2000;47(2):123-8.

8. Jensen MP. Review of measures of neuropathic pain. Curr Pain Headache Rep. 2006;10(3):159-66

9. de Andrade DC, Ferreira KA, Nishimura CM, Yeng LT, Batista AF, de Sá K, et al. Psychometric validation of the Portuguese version of the Neuropathic Pain Symptoms Inventory. Health Qual Life Outcomes. 2011;9:107.

10. Santos JG, Brito JO, de Andrade DC, Kaziyama VM, Ferreira KA, Souza I, et al. Translation to Portuguese and validation of the Douleur Neuropathique 4 questionnaire. J Pain. 2011;11(5):484-90.

11. Schestatsky P, Felix-Torres V, Chaves ML, Câmara-Ehlers B, Mucenic T, Caumo W, et al. Brazilian Portuguese validation of the Leeds Assessment of Neuropathic Symptoms and Signs for patients with chronic pain. Pain Med. 2011;12(10):1544-50.

12. Carvalho AB, Garcia JB, Silva TK, Ribeiro JV. Translation and transcultural adaptation of Pain Quality Assessment Scale (PQAS) to Brazilian version. Braz J Anesthesiol. 2016;66(1):94-104.

13. Bennett M. The LANSS Pain Scale: the Leeds assessment of neuropathic symptoms and signs. Pain. 2001;92(1-2):147-57

14. Backonja MM. Need for differential assessment tools of neuropathic pain and the deficits of LANSS pain scale. Pain. 2002;98(1-2):229-30; author reply 230-1.

15. Pérez C, Gálvez R, Insausti J, Bennett M, Ruiz M, Rejas J. [Linguistic adaptation and Spanish validation of the LANSS (Leeds Assessment of Neuropathic Symptoms and Signs) scale for the diagnosis of neuropathic pain]. Med Clin (Barc), 2006;127(13):485-91. Spanish.

16. Yucel A, Senocak M, Kocasoy Orhan E, Cimen A, Ertas M. Results of the Leeds assessment of neuropathic symptoms and signs pain scale in Turkey: a validation study. J Pain. 2004;5(8):427-32 7. Bennett MI, Smith BH, Torrance N, Potter J. The S-LANSS score for identifying pain of predominantly neuropathic origin: validation for use in clinical and postal research. J Pain. 2005;6(3):149-58.

8. Bennett MI, Bouhassira D. Epidemiology of neuropathic pain: can we use the screening tools? Pain. 2007;132(1-2):12-3.

19. Bouhassira D, Attal N, Alchaar H, Boureau F, Brochet B, Bruxelle J, et al. Comparison of pain syndromes associated with nervous or somatic lesions and development of a new neuropathic pain diagnostic questionnaire (DN4). Pain. 2005;114(1-2):29-36.

20. Mathieson S, Maher CG, Terwee CB, Folly de Campos T, Lin CW. Neuropathic pain screenin questionnaires have limited measurement properties. A systematic review. J Clin Epidemiol. 2015;68(8):957-66.

21. Krause SJ, Backonja MM. Development of a neuropathic pain questionnaire. Clin J Pain. 2003;19(5):306-14.

22. Backonja MM, Krause SJ. Neuropathic pain questionnaire--short form. Clin J Pain. 2003;19(5):315-6.

23. Freynhagen R, Baron R, Gockel U, Tolle TR. painDETECT: a new screening questionnaire to identify neuropathic components in patients with back pain. Curr Med Res Opin. 2006;22(10):1911-20.

24. Moreton BJ, Tew V, das Nair R, Wheeler M, Walsh DA, Lincoln NB. Pain phenotype in patients with knee osteoarthritis: classification and measurement properties of painDETECT and self-report Leeds assessment of neuropathic symptoms and signs scale in a cross-sectional study. Arthritis Care Res (Hoboken). 2015;67(4):519-28.

25. Alkan H, Ardic F, Erdogan C, Sahin F, Sarsan A, Findikoglu G. Turkish version of the painDETECT questionnaire in the assessment of neuropathic pain: a validity and reliability study. Pain Med. 2013;14(12):1933-43.

26. Portenoy R. Development and testing of a neuropathic pain screening questionnaire: ID Pain. Cur Med Res Opin. 2006;22(8):1555-65.

27. Padua L, Briani C, Truini A, Aprili I, Bouhassira D, Cruccu G, et al. Consistence and discrepancy of neuropathic pain screening tools DN4 and ID-Pain. Neurol Sci. 2013;34(3):373-7.

28. Galer BS, Jensen MP. Development and preliminary validation of a pain measure specific to neuropathic pain: the Neuropathic Pain Scale. Neurology. 1997;48(2):332-8.

29. Jensen MP, Gammaitoni AR, Olaleye DO, Oleka N, Nalamachu SR, Galer BS. The pain quality Jensen MP, Gammaitoni AR, Olaleye DO, Oleka N, Nalamachu SR, Galer BS. The pain quality
assessment scale: assessment of pain quality in carpal tunnel syndrome. J Pain. 2006;7(11):823-32. Bouhassira D, Attal N, Fermanian J, Alchaar H, Gautron M, Masquelier E, et al. Development and validation of the Neuropathic Pain Symptom Inventory. Pain. 2004;108(3):248-57. 